\title{
The Motivation of Physical Education Class in Liberals Arts Participation, Sports Personality, and Development of Sociality in the University Students
}

\author{
Do, Jea-Hyun, Jo, Yeong-Gwon, Lim, Jong-Sik, Yang, Chun-Ho
}

\begin{abstract}
To investigate the correlation in motivation of participation, sports personality, and development of sociality in the university students who went through general physical education, and to provide the basic data to enhance the general physical education, qualitatively. Population was set with the university students who went through the general physical education, and 340 copies of the final data were analyzed with SPSS 21.0 statistical program. Frequency analysis, correlation analysis, and multiple regression analysis were performed with the following conclusions. Motivation of participation in the university students who went through the general physical education showed the positive relationship with pleasure and technical development in sincerity of sports personality. In addition, motivation of participation showed positive relationship with pleasure, technical development, and health/physical strength in sociability of sociality development. Also, autonomy showed positive relationship with pleasure, technical development, sociality, and health/physical fitness, and activity showed the positive relationship with pleasure, sociality, and health/physical strength..
\end{abstract}

Keywords :Sports Character, Social, Health, Development, Motivation, Physical Fitness.

\section{INTRODUCTION}

Currently, liberal education has been thought as a new direction of the education in the domestic universities. Hence, the discussion on the importance of liberal education has been actively performed in the overall society. Government also seeks the qualitative changes of the university education by administrative and economic supports as the alternative policy. Knowledge transferring system in the modern education is hard to catch up with the changes of the times, and it is difficult to adapt in the modern society with fragmented and narrow-minded knowledge [1].

Therefore, it is considered that the needs of converging education with multiple disciplines are empathized and

Revised Manuscript Received on July 22, 2019.

Do, Jea-Hyun, Hanseo University, Dept. of Marine Sports, Seosan,31962, Korea

Jo, Yeong-Gwon, Gwangju University of Education, Dept. of Physical Education, Gwangju,61204, Korea

Lim, Jong-Sik, Kunsan National University, Dept. of Physical Education, Kunsan,54150, Korea

Yang, Chun-Ho, Hanseo University, Dept. of Marine Sports, Seosan,31962, Korea liberal education in the universities will play a central role to realize this converging education. First, general physical education is one of liberal educations. Changes of liberal education depend on the changes of general physical education, inevitably. However, the universities dealing with general physical education has not yet set the direction. Physical education in the curricula of primary, middle, and high schools show the continuous expansion trend by regular classes and activation of sport club activities while the policy of sports activities in the universities rely on the independent decision by each. The trend not to be interested in the sports activities in the universities was remarkable due to reasons such as employment support and university evaluation. Moreover, the university students' interest in their sports activities had been low since 2010 in terms of national policy [2]. Because of these results, the universities accepted the reality of reduction or elimination of the subject, general physical education, without establishments of the countermeasures and strategies [3].

Generally, sports activities are known to be the best means of learning about the roles and norms of the society such as urging development of ethics, sound citizenship, and development of personality [4]. In fact, fair play, teamwork, consideration, and respect acquired in the courses of sports activities are considered to develop the attitude and value to respect himself/herself as well as others contributing to the development of personality and sociality [5]. In addition, sports activities develop the strong mental strength to overcome the difficulties in living a life upon enhancement of desirable sociality and ethics [6].

General physical education based on sports activities should enhance the desirable ethics and sociality of the university students not only promoting their energy in the university life but also empathizing to develop them as the lifelong amateur athletes. University students can be considered as preliminary members of the community in that stage before being released to the society. Without preparation of the personality for these university students, self-oriented attitude will appear strongly to be able to deepen the conflicts among members [7]. University period amid the traditional courses of human development can be the stage where development of personality is complete. 
Yet, personality will be developed throughout the whole life, and personality education especially for the university students who are preliminary members of the community is more important than any other periods in their lives [8]. Also, it is necessary to strengthen the personality education in the university since the professors in the universities rated the priorities on creative thinking capability, morality, and development of personality in the core competencies and curricula of the university students [9]. Therefore, continuous personality education should be implemented even in the universities [10].

After announcement of 2009 amended curricula, there have requests that personality education be taught in all the subjects as a keyword in the future society [11]. Personality is considered as the capability of the community member amid the changing sociocultural context and unique individual behaviors [12]. According to Personality Education Enhancement Act implemented in 2015, the subjects related to personality were taught to strengthen the teaching capability of preliminary teachers on their personality education [13]. In fact, some domestic universities use the sports activities for the personality education. A theoretical subject of Sports Personality Education teaches how to deal with sports personality education by the teachers of physical education in I University. Teaching is performed on how to develop personality education by the lifelong sports subject in $\mathrm{S}$ University. From these, the efforts to enhance the personality education should be made upon developments of multiple personality education programs through sports in the universities [14].

On the other hand, sociality means the capability of people to make relate with others upon adaptation to the surrounding environment [15]. The higher the sociality, the higher adaptation in a variety of sociocultural environments, demonstrating active interaction with the community members [16]. Sociality in Sports Sociology is the transformation or generalization process of learned functions, characteristics, values, attitudes, knowledge, and tendency, from sports into the other social phenomena [17]. Sociality has a representative theory as social learning theory. The social learning theory means to experience the socialization by various experiences, modeling, or other linguistic persuasion within the certain boundary. In other words, participations in the sports activities can develop sociality in the daily lives, directly and indirectly, as well as health and ultimately social stability [18]. In summary, education of personality and sociality is a significant contribution in solving the social problems as well as to provide them with social maturity [19].

Upon reviewing previous studies on the developments of personality and sociality with respect to university students, Jang [14], suggested the proper causal relationship model between sociopsychological atmosphere and sports personality. Cho, Lee and Hyung [20] suggested the developmental factors of sociality by club activities in the universities, and Yoon and Kang [21] reported that the class satisfaction level of the participants of general physical education was the factor to influence their development of sociality.

These previous studies showed the outcomes that university students' participations in the sports positively influenced their developments of personality and sociality. Nonetheless, the objective of this study was to analyze the relationship between personality and development of sociality according to the participation motivation in the general physical education since few studies had been conducted on the developments of personality and sociality in the students who took the classes of general physical education. Thus, this study has the meaning to review the importance of sports personality and sociality development acquired by participation motivation in the general physical education and to provide the qualitative enhancement of general physical education classes in the current universities as well as the basic data upon revealing the positive effects of the classes in the universities.

\section{METHODS}

\subsection{Study subjects}

The study subjects were 350 students who went through general physical education in H University located in S City, South Choongchung Province. After collection of the survey sheets, total 340 survey sheets were used for the study analysis excluding 10 copies deemed as insincere answers or did not meet the study goals.

\subsection{Study tools}

The survey questionnaires were used as the data collection tool to investigate the relationship between sports personality and development of sociality. They were also used to investigate the participation motivation of the students who took the class of general physical education. The survey consists of total 50 questionnaires; 5 questionnaires on sociodemographic variables including gender, age, subjective health status, and exercise participation time; 17 questionnaires on participation motivation; 14 questionnaires on sports personality; and 15 questionnaires on development of sociality. Translated version by Jung [23] of SMS-28 (sport motivation scale) by Vallerand and Bissonnette [22] was used for the questionnaires on participation motivation. The survey sheet with proven reliability in Kwon's study [24] were amended and modified to meet the objectives of this study, consisting of total 17 questionnaires on internal and external motivations as the sub-indexes. With respect to the sports personality, proven survey sheet with reliability $(\alpha=.82)$ in Park's study [14] based on the survey sheet developed by Park [25] was amended and modified, consisting of total 14 questionnaires on sincerity, cooperation, justice, and consideration as the sub-indexes. In terms of sociality development, the questionnaires with proven reliability in Kim [26] and Chae [27] et al., studies were amended and modified to meet the objectives of this study, consisting of total 15 questionnaires on sociability, 
autonomy, and activity as the sub-indexes. 5-point Likert Scale was used for all the questionnaires, from 1 point with 'never' to 5 point with 'very likely.'

\subsection{Validity and reliability}

\subsubsection{Motivation of participation}

As shown in "Table 1", Bartlett's unit matrix was 4132.162 (Sig=.001) and KMO index was 0.918, demonstrating the appropriateness of variable selections, upon the factor analysis on the motivation of participation. Based on this, 4 factors were extracted from factor analysis with 16 questionnaires, representing $77.2 \%$ of total variables. Factor loads on the motivation of participation were.691-.846 for pleasure, .728-.865 for technical development, .680-.805 for friendship, and .760-.860 for health/physical fitness. Reliability values were .809 for pleasure, .817 for technical development, .826 for sociability, and .825 for health/physical fitness, which represented the reliable level.

Table 1: Relationship between ethics and self-management behaviors

\begin{tabular}{|l|l|l|l|l|l|}
\hline item & Pleasure & $\begin{array}{l}\text { Technical } \\
\text { development }\end{array}$ & Friendship & $\begin{array}{l}\text { Health/Physi } \\
\text { cal fitness }\end{array}$ & $h^{2}$ \\
\hline Factor 1 & .777 & .354 & .221 & .155 & .803 \\
Factor 2 & .846 & .271 & .208 & .156 & .856 \\
Factor 3 & .838 & .266 & .223 & .186 & .857 \\
Factor 4 & .783 & .310 & .229 & .187 & .796 \\
Factor 5 & .691 & .301 & .333 & .153 & .702 \\
Factor 6 & .134 & .132 & .805 & .079 & .689 \\
Factor 7 & .246 & .207 & .748 & .209 & .706 \\
Factor 8 & .280 & .116 & .680 & .286 & .635 \\
Factor 9 & .246 & .132 & .739 & .248 & .685 \\
Factor 10 & .001 & .205 & .225 & .836 & .791 \\
Factor 11 & .260 & .099 & .176 & .860 & .848 \\
Factor 12 & .321 & .073 & .266 & .760 & .756 \\
Factor 13 & .287 & .853 & .108 & .062 & .825 \\
Factor 14 & .260 & .829 & .141 & .157 & .800 \\
Factor 15 & .375 & .728 & .249 & .089 & .741 \\
Factor 16 & .257 & .865 & 152 & .170 & .865 \\
\hline Eigenvalue & 8.110 & 1.933 & 1.218 & 1.094 & \\
Variance\% & 50.688 & 12.081 & 7.611 & 6.840 & \\
Cumulative & 50.688 & 62.769 & 70.380 & 77.220 & \\
\hline Reliability & .809 & .817 & .825 & \\
\hline Kaiser-Meyer-Olkin $=.918$ & & \\
Bartlett of matrix unit $\left(\mathrm{x}^{2}=4132.778, \mathrm{df}=120, \mathrm{p}=.000\right)$ & \\
\hline
\end{tabular}

\subsubsection{Sports personality}

As shown in "Table 2", Bartlett's unit matrix was 1368.787 (Sig=.001) and KMO index was .757, demonstrating the appropriateness of variable selections, upon the factor analysis on sports personality. Based on this, four factors were extracted from factor analysis with 12 questionnaires, representing $69.7 \%$ of total variables. Factor loads on sports personality were $.849-.874$ for sincerity, .607 - .790 for cooperation, $.841-.879$ for justice, and $.858-.871$ for consideration. Reliability values were .807 for sincerity, .862 for cooperation, .855 for justice, and .858 for consideration, which represented the reliable level.
Table 2: Validity and reliability on sports personality

\begin{tabular}{|l|l|l|l|l|l|}
\hline item & sincerity & cooperation & justice & consideration & $\mathrm{h}^{2}$ \\
\hline Factor 1 & .856 & .003 & -.036 & -.036 & .736 \\
Factor 2 & .849 & -.019 & .007 & .022 & .722 \\
Factor 3 & .860 & -.005 & .017 & -.030 & .741 \\
Factor 4 & .874 & -.061 & .052 & .033 & .772 \\
Factor 5 & .041 & .111 & .034 & .871 & .774 \\
Factor 6 & -.053 & .129 & .068 & .858 & .760 \\
Factor 7 & .040 & .176 & .841 & .087 & .747 \\
Factor 8 & -.012 & .156 & .879 & .007 & .798 \\
Factor 9 & -.053 & .695 & .229 & .018 & .639 \\
Factor 10 & -.026 & .790 & -.103 & .002 & .636 \\
Factor 11 & .041 & .607 & .354 & .229 & .647 \\
Factor 12 & -.023 & .728 & .163 & .173 & .687 \\
\hline Eigenvalue & 3.007 & 2.852 & 1.364 & 1.135 & \\
Variance\% & 25.057 & 23.768 & 11.370 & 9.459 & \\
Cumulative & 25.057 & 48.825 & 60.195 & 69.654 & \\
\hline Reliability & .807 & .862 & .855 & .858 & \\
Kaiser-Meyer-Olkin $=.757$ & \\
Bartlett of matrix unit $\left(\mathrm{x}^{2}=1368.787, \mathrm{df}=66, \mathrm{p}=.000\right)$ &
\end{tabular}

\subsubsection{Development of sociality}

Asshown in "Table 3", Bartlett's unit matrix was 2877.443 (Sig=.001) and KMO index was .918, demonstrating the appropriateness of variable selections, upon the factor analysis on the development of sociality. Based on this, three factors were extracted from factor analysis with 14 questionnaires, representing $69.1 \%$ of total variables. Factor loads on the development of sociality were $.706-.814$ for sociability, $.728-.806$ for autonomy, and .579 - .856 for activity. Reliability values were .824 for sociability, .817 for autonomy, and .817 for activity, which represented the reliable level.

Table 3: Validity and reliability on the development of sociality

\begin{tabular}{|l|l|l|l|l|}
\hline item & Sociability & autonomy & activity & h2 \\
\hline Factor 1 & .706 & .193 & .155 & .660 \\
Factor 2 & .788 & .167 & .281 & .728 \\
Factor 3 & .814 & .162 & .217 & .735 \\
Factor 4 & .785 & .233 & .229 & .723 \\
Factor 5 & .785 & .284 & .212 & .742 \\
Factor 6 & .224 & .779 & .155 & .681 \\
Factor 7 & .128 & .806 & .286 & .747 \\
Factor 8 & .237 & .773 & .315 & .753 \\
Factor 9 & .325 & .728 & .200 & .676 \\
Factor 10 & .244 & .380 & .579 & .639 \\
Factor 11 & .380 & .316 & .613 & .620 \\
Factor 12 & .337 & .363 & .667 & .690 \\
Factor 13 & .276 & .274 & .756 & .722 \\
Factor 14 & .123 & .092 & .856 & .757 \\
\hline Eigenvalue & 7.117 & 1.465 & 1.092 & \\
Variance\% & 50.839 & 10.465 & 7.798 & \\
Cumulative & 50.839 & 61.303 & 69.102 & \\
\hline Reliability & .824 & .817 & .817 & \\
\hline
\end{tabular}

Kaiser-Meyer-Olkin $=.918$

Bartlett of matrix unit $\left(\mathrm{x}^{2}=2877.443, \mathrm{df}=91, \mathrm{p}=.000\right)$

\subsection{Data processing and analysis}

Study hypotheses were verified using 340 survey sheets to investigate the relationship in the motivation of participation, sports personality, and the development of sociality in the university students who took the class of general physical education. With respect 
The Motivation of Physical Education Class in Liberals Arts Participation, Sports Personality, and Development of Sociality in the University Students

to the data processing, correlation analysis and multiple regression analysis were performed to understand the relationship between sports personality and the development of sociality according to the motivation level of participation. Statistically significance level was $\mathrm{p}<.05$ in all the analyses.

\section{RESERCH RESULTS}

\subsection{Results of correlation analysis}

Correlation analysis was performed to understand the relationship in the motivation of participation, sports personality, and the development of sociality in the university students who went through general physical education. The outcomes were as shown in "Table 4".

Table 4: Relationship in motivation of participation, sports personality, and the development of sociality

\begin{tabular}{|c|c|c|c|c|c|c|c|c|c|c|c|}
\hline & A & B & C & D & $E$ & $\mathrm{~F}$ & $\mathrm{G}$ & $\mathrm{H}$ & I & G & $\mathrm{K}$ \\
\hline A & 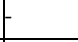 & & & & & & & & & & \\
\hline B & $396^{* * *}$ & & & & & & & & & & \\
\hline C & .024 & -.027 & - & & & & & & & & \\
\hline $\mathrm{D}$ & $.142^{*}$ & .063 & $.441^{* * *}$ & - & & & & & & & \\
\hline$E$ & $.453^{* * * *}$ & $421^{* * * *}$ & .055 & .002 & & & & & & & \\
\hline$F$ & $.482^{* * * *}$ & $403^{* * *}$ & $.225^{* *}$ & $.299^{* * * *}$ & $318^{* * *}$ & & & & & & \\
\hline $\mathrm{G}$ & $.283^{* * * *}$ & $.145^{*}$ & $.424^{* * *}$ & $.326^{* * * *}$ & $.225^{* * * *}$ & $.423^{* * * *}$ & & & & & \\
\hline $\mathrm{H}$ & $374^{* * *}$ & $.210^{* * * *}$ & $.221^{* *}$ & .116 & $314^{* * * *}$ & $463^{* * * *}$ & $.450^{* * * *}$ & & & & \\
\hline I & $.803^{* * *}$ & $314^{* * *}$ & .069 & .058 & $.481^{* * * *}$ & $.345^{* * * *}$ & $.264^{* * * *}$ & $436^{* * *}$ & & & \\
\hline $\mathrm{J}$ & $.424^{* * * *}$ & $.553^{* * * *}$ & .134 & .129 & $.492^{* * * *}$ & $.390^{* * * *}$ & $.300^{* * *}$ & $.323^{* * * *}$ & $.464^{* * * *}$ & & \\
\hline $\mathrm{K}$ & $241^{* * * *}$ & $.215^{*}$ & $.567^{* * * *}$ & $.220^{* *}$ & $.272^{* * * *}$ & $.281^{* * * *}$ & $.412^{* * *}$ & $.358^{* * *}$ & $187^{* *}$ & $.365^{* * *}$ & \\
\hline
\end{tabular}

A:pleasure. B: technical development. C: friendship. D: health/physical fitness E: sincerity. F: cooperation. G: justice. $\mathrm{H}$ : consideration. I: sociability. J: autonomy. K: activity.

With respect to the correlation between motivation of participation and sports personality, pleasure, technical development, and friendship showed positive correlation with sincerity as follows, respectively, ( $r=.794),(r=.768)$, $(r=.529)$. For the correlation between the motivation of participation and the development of sociality, pleasure showed positive correlations with sociability ( $\mathrm{r}=.509)$, autonomy ( $\mathrm{r}=.540)$, and activity $(\mathrm{r}=.553)$. Technical development showed positive correlations with sociability $(\mathrm{r}=.540)$, autonomy $(\mathrm{r}=.622)$, and activity $(\mathrm{r}=.481)$. Friendship showed positive correlations with sociability ( $\mathrm{r}=.349)$, autonomy ( $\mathrm{r}=.481)$, and activity ( $\mathrm{r}=.494)$. Health/physical fitness showed positive correlations with sociability ( $\mathrm{r}=.519)$, autonomy $(\mathrm{r}=.311)$, and activity $(\mathrm{r}=.473)$.

\subsection{Relationship between motivation of participation and sports personality}

\subsubsection{Relationship between motivation of participation in general physical education and sincerity}

Table 5: Relationship motivation of participation and sincerity

\begin{tabular}{|c|c|c|c|c|c|}
\hline & $\mathrm{B}$ & SE & Beta & $t$ & $\mathrm{p}$ \\
\hline Constant & .244 & .120 & & $2.029^{*}$ & .043 \\
\hline Pleasure & .442 & .035 & .513 & $12.805^{* * *}$ & .000 \\
\hline Technical development & t. 471 & .038 & .441 & $12.476^{* * *}$ & .000 \\
\hline Friendship & .036 & .027 & .043 & 1.328 & .185 \\
\hline Health/physical fitness & -.003 & .032 & -.003 & -.093 & .926 \\
\hline $\mathrm{R}^{2}=.767, \mathrm{~F}=275.990^{* * * *}$ & & & & & \\
\hline
\end{tabular}

As shown in "Table 5", significant correlation was found between motivation of participation in general physical education and sincerity with $\mathrm{F}=275.990$ under the significance level of $\mathrm{p}<.001$ with explanation of regression equation with $76.7 \% \quad\left(\mathrm{R}^{2}=.767\right)$, upon the results of relationship between motivation of participation in general physical education and sincerity. In detail, the relationship between motivation of participation and sincerity showed the order of pleasure $(\beta=.513, \mathrm{t}=12.805)$ and technical development $(\beta=.441, \mathrm{t}=12.476)$.

\subsubsection{Relationship between motivation of participation in general physical education and cooperation}

Table 6: Relationship motivation of participation and cooperation

\begin{tabular}{|c|c|c|c|c|c|}
\hline & B & SE & Beta & $t$ & $\mathrm{p}$ \\
\hline Constant & 4.575 & .194 & & $23.580^{* *}$ & .000 \\
\hline Pleasure & .014 & .056 & .021 & .259 & .796 \\
\hline Technical development & .000 & .061 & .000 & -.005 & .996 \\
\hline Friendship & .003 & .043 & .004 & .061 & .952 \\
\hline Health/physical fitness & -.021 & .052 & -.031 & -.413 & .680 \\
\hline \multicolumn{6}{|l|}{$\mathrm{R}^{2}=.001, \mathrm{~F}=.044$} \\
\hline
\end{tabular}

Asseen in "Table 6", the correlation between motivation of participation in general physical education and cooperation was insignificant with $\mathrm{F}=.044$ under the significance level of p>.05 with explanation of regression equation with $0.1 \%$ $\left(\mathrm{R}^{2}=.001\right)$, upon the results of relationship between motivation of participation in general physical education and cooperation.

\subsubsection{Relationship between motivation of participation in general physical education and justice}

Table 7: Relationship motivation of participation and justice

\begin{tabular}{|l|l|l|l|l|l|}
\hline & $\mathrm{B}$ & SE & Beta & $t$ & $\mathrm{p}$ \\
\hline Constant & 4.482 & .164 & & $27.383^{* * *}$ & .000 \\
\hline Pleasure & .011 & .047 & .019 & .232 & .817 \\
\hline Technical development & .035 & .051 & .049 & .676 & .500 \\
\hline Friendship & .033 & .037 & .060 & .903 & .367 \\
\hline Health/physical fitness & -.028 & .043 & -.048 & -.653 & .514 \\
\hline $\mathrm{R}^{2}=.009, \mathrm{~F}=.732$ \\
\hline
\end{tabular}

Asseen in "Table 7", the correlation between motivation of participation in general physical education and justice was insignificant with $\mathrm{F}=.732$ under the significance level of $p>.05$ with explanation of 
regression equation with $0.9 \%\left(\mathrm{R}^{2}=.009\right)$, upon the results of relationship between motivation of participation in general physical education and justice.

\subsubsection{Relationship between motivation of participation in general physical education and consideration}

Table 8: Relationship motivation of participation and consideration

\begin{tabular}{|c|c|c|c|c|c|}
\hline & B & SE & Beta & $t$ & $\mathrm{p}$ \\
\hline Constant & 4.560 & .161 & & $28.278^{* * * *}$ & .000 \\
\hline Pleasure & -.032 & .046 & -.057 & -.686 & .493 \\
\hline Technical development & -.042 & .051 & -.060 & -.827 & .409 \\
\hline Friendship & .055 & .036 & .101 & 1.515 & .131 \\
\hline Health/physical fitness & .018 & .043 & .031 & 416 & .678 \\
\hline $\mathrm{R}^{2}=.008$ & & & & & \\
\hline
\end{tabular}

Asseen in "Table 8", the correlation between motivation of participation in general physical education and consideration was significant with $\mathrm{F}=.697$ under the significance level of p>.05 with explanation of regression equation with $0.8 \%$ $\left(\mathrm{R}^{2}=.008\right)$, upon the results of relationship between motivation of participation in general physical education and consideration.

\subsection{Relationship between motivation of participation and development of sociality}

\subsubsection{Relationship between motivation of participation} in general physical education and sociability

Table 9: Relationship motivation of participation and sociability

\begin{tabular}{|l|l|l|l|l|l|}
\hline & $\mathrm{B}$ & SE & Beta & $t$ & $\mathrm{p}$ \\
\hline Constant & 1.190 & .206 & & $5.785^{* *}$ & .000 \\
\hline Pleasure & 159 & .059 & 181 & $2.689^{* *}$ & .008 \\
\hline Technical development & .180 & .065 & .166 & $2.787^{* *}$ & .006 \\
\hline Friendship & 050 & .046 & .059 & 1.092 & .276 \\
\hline Health/physical fitness & .274 & .055 & .300 & $5.009^{* * *}$ & .000 \\
\hline $\mathrm{R}^{2}=.342, \mathrm{~F}=43.508^{* * *}$ \\
\hline
\end{tabular}

As shown in "Table 9", significant correlation was found between motivation of participation in general physical education and sociability with $\mathrm{F}=43.508$ under the significance level of $\mathrm{p}<.001$ with explanation of regression equation with $34.2 \% \quad\left(\mathrm{R}^{2}=.342\right)$, upon the results of relationship between motivation of participation in general physical education and sociability. In detail, the relationship between motivation of participation and sociability showed the order of health/physical fitness $(\beta=.300, \mathrm{t}=5.009)$, pleasure $(\beta=.181, \mathrm{t}=2.689)$, and technical development $(\beta=.166, \mathrm{t}=2.787)$.

\subsubsection{Relationship between motivation of participation in general physical education and autonomy}

Table 10: Relationship motivation of participation and autonomy

\begin{tabular}{|l|l|l|l|l|l|}
\hline & B & SE & Beta & $t$ & $\mathrm{p}$ \\
\hline Constant & 1.002 & .183 & & $5.470^{* * * *}$ & .000 \\
\hline Pleasure & .272 & .053 & .316 & $5.167^{* * *}$ & .000 \\
\hline
\end{tabular}

\begin{tabular}{|l|l|l|l|l|l|}
\hline Technical development & .443 & .058 & .415 & $7.695^{* * *}$ & .000 \\
\hline Friendship & .132 & .041 & .158 & $3.205^{* * *}$ & .001 \\
\hline Health/physical fitness & -.132 & .049 & -.148 & $-2.715^{* *}$ & .007 \\
\hline $\mathrm{R}^{2}=.459, \mathrm{~F}=70.948^{* * * *}$ \\
${ }^{*} \mathrm{p}<.001$
\end{tabular}

Asshown in "Table 10", significant correlation was found between motivation of participation in general physical education and autonomy with $\mathrm{F}=70.948$ under the significance level of $\mathrm{p}<.001$ with explanation of regression equation with $45.9 \% \quad\left(\mathrm{R}^{2}=.459\right)$, upon the results of relationship between motivation of participation in general physical education and autonomy. In detail, the relationship between motivation of participation and autonomy showed the positive correlations in the order of technical development $(\beta=.415, \mathrm{t}=7.695)$, joy $(\beta=.316, \mathrm{t}=5.167)$, and friendship $(\beta=.158, \mathrm{t}=3.205)$, while negative correlation with health/physical strength $(\beta=.148, \mathrm{t}=-2.715)$.

\subsubsection{Relationship between motivation of participation in general physical education and activity}

Table 11: Relationship motivation of participation and

\begin{tabular}{|l|l|l|l|l|l|}
\hline \multicolumn{7}{|c|}{ activity } \\
\hline & B & SE & Beta & $t$ & $\mathrm{p}$ \\
\hline Constant & .867 & .200 & & $4.337^{* * * *}$ & .000 \\
\hline Pleasure & .244 & .057 & .275 & $4.250^{* * *}$ & .000 \\
\hline Technical development & .097 & .063 & .088 & 1.538 & 125 \\
\hline Friendship & .220 & .045 & .256 & $4.903^{* * *}$ & .000 \\
\hline Health/physical fitness & .141 & .053 & .153 & $2.659^{* * *}$ & .008 \\
\hline $\mathrm{R}^{2}=.392, \mathrm{~F}=53.960^{* * *}$ & & & \\
\hline
\end{tabular}

As shown in "Table 11", significant correlation was found between motivation of participation in general physical education and activity with $\mathrm{F}=53.960$ under the significance level of $\mathrm{p}<.001$ with explanation of regression equation with $39.2 \%\left(\mathrm{R}^{2}=.392\right)$, upon the results of relationship between motivation of participation in general physical education and activity. In detail, the relationship between motivation of participation and activity showed the order of pleasure $(\beta=.275, \quad \mathrm{t}=4.250), \quad$ friendship $(\beta=.256, \mathrm{t}=4.903)$, and health/physical strength $(\beta=.153, \mathrm{t}=2.659)$.

\section{DISCUSSION}

According to the results of this study, motivation of participation and sports personality in the university students who went through general physical education showed positive relationship with joy and technical development in sincerity. Despite multiple previous studies claiming the significance of sports activities on the development of personality [28-30], this study showed positive relationship only in sincerity. Personality could be an inborn character from the birth as a nature of a human being. In the end, the university students who went through general physical education could be considered with the goal to acquire credit only. In the pedagogic perspective, personality has the value-oriented character that implicates the humanity and the personality defined in the personality education, and can be acquired by efforts rather than inherited [31]. Students going through general physical education in the universities are required to develop their personalities in view of education rather than participating for 
simple credit earning and graduation purpose only. Sports personality, in particular, is developed by participation in the sports with personality education [33]. Therefore, objective understanding of participation motivation in the students can play a role to enhance its relationship with sports personality, effectively. Participation motivation in the general physical education and their development of sociality showed positive relationship with joy,

technical development, and health/physical strength in sociability. Autonomy showed positive relationship with pleasure, technical development, sociability, and health/physical fitness, and activity showed the positive relationship with joy, sociability, and health/physical strength. Indirectly, the study showed that the classes of general physical education in the universities were performed mainly with joy and happiness rather than acquiring special skills that rely on winning in the sports. Also, the students acknowledged the positive relationship with health and physical strength upon setting and performing the exercise to meet their capabilities rather than immoderate exercise. This is consistent with a study with the subjects of middle school students who participated in the school sports clubs claiming the significantly positive relationship between sociability and health/physical fitness [34], and Lee's [15] study reporting the positive impacts of physical exercise participation after school and participation motivation of the middle school students on their developments of sociality [35]. Likewise, general physical education can be used develop sociality of the students as it affects them positively.

\section{CONCLUSION}

The objectives of this study were to investigate the correlation in motivation of participation, sports personality, and development of sociality in the university students who went through general physical education and to provide the basic data to enhance the general physical education, qualitatively. The study subject were university students who went through the general physical education, and 340 copies of the final data were analyzed with SPSS 21.0 statistical program. Frequency analysis, correlation analysis, and multiple regression analysis were performed with the following conclusions. Motivation of participation in the university students who went through general physical education showed positive correlation with pleasure and technical development in sincerity of sports personality. In addition, motivation of participation showed positive correlation with pleasure, technical development, and health/physical strength in sociability of sociality development. Autonomy showed positive correlation with pleasure, technical development, sociality, and health/physical fitness, and activity showed positive correlation with pleasure, sociality, and health/physical strength.

\section{REFERENCES}

1. S.I. Kim, H.S. Lee, H.J. Kim, M.H. Seo, "Flow and Development Strategies of Liberal Education at University". Korean Journal of General Education. 7(1),11-39, 2013.

2. S.Y. Kwon, M.H. Kwon, S.H. Hwang, H.B. Kim, "Perception of College Students about the Sports Activities". Journal of Korean Society of Sport Policy. 13(3), 107-120, 2015.

3. J.A. You, "Critique on Educational \& Competitive Power of Physical Education as Liberal Education in Korea Higher Education". Korean journal of physical education. 52(6), 205-216, 2013.

4. B.J. Lim, E.H. Koh, Y.L. Chung, "Sport Participation in Korea: Growth and Changes". Korean journal of physical education. 39(1), 222-232, 2000 .

5. M.S. Ko, E.C. Kwak, "Relationship between Sex, Sport Character, Empathy and Pro-social Behavior among Elementary School Student who experienced School Sport Club". The Korean Journal of the Elementary Physical Education. 21(3), 17-33, 2015.

6. S.W. Choi, B.J. Oh, N.S. Back, "The Effect of Taekwondo Training Satisfaction of Middle and High School Students on Personality Development and School Life Adaptation". The Korea Journal of Sport. 15(4), 83-92, 2017.

7. H.J. Ryu, E.K. Park, "A Study on Environmental Designs for a Safe Campus from Crimes- Based on the Collegian's Perceptions of on-campus Crimes and Fear of Crimes". The Architectural Institute of Korea. 26(8), 97-106, 2010

8. B.R. Kang, S.R. Lee, "The Direction of Character Education in College: focused on the current character education programs in domestic and foreign universities". Journal of Women's Studies. 28, 69-102, 2013.

9. H.S. Kim, "Exploring students' creativity-core competencies in higher education curriculum from professors' perspectives". The Journal of creativity education. 13(3), 145-163, 2013.

10. H.J. Ji, "An Inquiry into the Awareness on the Liberal and Character Education among College Students". Korean Journal of General Education. 7(5), 433-466, 2013.

11. H.M. Jo, S.M. Jeon, "Revised Physical Education National Curriculum`s Compositional Direction". The Journal of Korea elementary education. 21(3), 31-44, 2011

12. S.H. Han, H.Y. Jeong, M.J. Lee, S.H. Kim, J.S. Jeon, I.S. Park Understanding of pedagogy. Yangseowon Publishing Company. 2013.

13. The Legislative Office[Internet]. Personality education promotion act, http://www.moleg.go.kr/ (website), 2015.

14. C.Y. Jang, "The Structural Relationship of Perceived Social Psychological Climate on Sport Character among College Students Participating in Exercise". Korean Society of Sport Psychology. 28(2), 1-11, 2017.

15. J.Y. Lee, J.H. Kim, "The Effects of Physical Activity According to Participation Degrees on Development of Sociability among Middle School Student. Korea sport research..15(4), 1011-1027, 2004.

16. Leonard. A sociological perspective of sport Minneapolis, MN: Burgess Reading, MA: Addison-institute. 1980.

17. B.J. Lim, Sports sociology introduction. Rainbow-books Publishing Company. 2010..

18. J.H. Dong, K.H. Lee, K.J. Park, "The Analysis of Emotion, Sociality and Life Attitude of Elementary School Students Training for Taekwondo". Journal of coaching development. 11(4), 119-127, 2009.

19. E.J. Cha, Y.J. Kim, "Analysis of the Differences in Personalities of Adolescent Participating in School Sports Clubs". Korean journal of physical education. 53(1), 25-34, 2014.

20. I.R. Cho, J.W. Lee, K.A. Hyung, "The relationship among the exercise-fun factors, physical self-concept and well-being-oriented behavior of taekwondo club participation in university". Korean Journal of Sports Science. 24(1), 2015, 153-164.

21. S.W. Yoon, S.T. Kang, "The Effect of the Class Satisfaction on Exercise Commitment and the Exercise Adherence Intention for the Participants in the Golf for General Education at a University". Journal of Golf Studies. $8(2), 2014,99-112$.

22. R.J. Vallernad, R. Bissonnette, "Intrinsic extrinsic and motivational style as predictors of behavior: A Prospective study". Journal of Personality and Social Psychology. 60, 599-620, 1992.

23. Y.G. Jung, "An Exploratory Factor Analysis of Sport Participation Motivation”. Korean Society of Sport Psychology. 9(1), 113-131, 1998.

24. S.Y. Kim, K.S. Lee, "Structural Relationships between Achievement Goal Orientations of a Student Taking Cultural Physical Education Class, and Commitment to Exercise, Class Satisfaction and Recommendation Intention". Journal of Sport and Leisure Studies.47(1), 45-56, 2012.

25. J.J. Park, "Can sports build Character? The theoretical, empirical grounds and tasks of character education through sports". The Journal of Curriculum Studies. 29(3), 173-202, 2011. 
26. J.H. Kim, "The Effects of Physical Activity according to Participation Availability on Development of Sociability among Middle School Student. Korea sport research". 16(6), 799-813, 2005.

27. J.S Chae, "The Effect on the Social Development of the University Students' Participation in Sports". Journal of Korean Society of Sport Policy. 12, 45-56, 2008.

28. S.B. Lee, K.K. Kim, "A Study on Sports Participation, Creativity, Personality and Characteristics". Korean Society for Holistic Convergence Education. 19(4), 159-172, 2015.

29. H.I. Kwon, S.H. Woo, Y.J. Kang, "The Effect of Intensive After-school New sports Program on Middle School Students' Personality Development". Korean journal of physical education. 53(2), 215-226, 2014.

30. H.M. Jun, C.H. Lee, S.B. Na, "Relationship between Type and Level of Sports Activity Participation and Creative Personality". Korean Journal of Sports Science. 22(6), 669-680, 2013

31. J.W. Kim, "Efficacy Analysis of Developed Course for Promoting Character Education with Women's University Students". Journal of Digital Convergence. 13(11), 481-491, 2015.

32. Korean Educational Research Association. Personality education. Moonumsa Publishing Company. 1998.

33. P. Arnold, Sport, ethics and education. Bloomsbury Publishing. 1997.

34. H.J. Lee, M.S. Hong, "The Influence of Middle School Students Participation in Dance Class during Sport Club Activity on Dance Awareness, Physical Education Enjoyment, and Exercise Adherence". Official Journal of Korean Society of Dance Science. 32(1), 31-45, 2015.

35. S.H. Lee, "Effects of Participation Motivation and Attitudes Toward Sports on Development of Sociability Among Middle Schoolers Participating in After-school Sports Activities". Korean journal of physical education. 49(6), 103-113, 2010.

\section{AUTHORS PROFILE}

Doo, Jae-Hyun, Hanseo University graduate school physical education master

Jo, Yeong-Gwon, Professor Dept. of Physical Education, Gwangju University of Education, Korea

Lim, Jong -Sik, Ph.D. Student, Dept. of Physical Education, Korea

Yang, Chun-Ho, Professor, Dept. of Leisure Marine Sports, Hanseo University, Korea

Chief of Library, Hanseo University, Korea 